\title{
Zero Secondary Transmission from Three Traveling COVID-19 Cases in China: A Case for Social Responsibility from the General Public in Stemming the Chain of Transmission
}

\author{
Rongfei Su',*, Yuqi Hu ${ }^{1, *}$, Zhenpeng Liao $\mathbb{D}^{1, *}$, Kai Sen $\operatorname{Tan}^{2}$, Haiyu Hong $\mathbb{D}^{\prime}$, \\ Yunping $\mathrm{Fan}^{3}$

\begin{abstract}
'Allergy Center, Department of Otolaryngology, The Fifth Affiliated Hospital of Sun Yat-sen University, Zhuhai, People's Republic of China; ${ }^{2}$ Department of Otolaryngology, National University of Singapore, National University Health System, Singapore; ${ }^{3}$ Department of Otolaryngology, The Seventh Affiliated Hospital of Sun Yat-sen University, Shenzhen, People's Republic of China
\end{abstract}

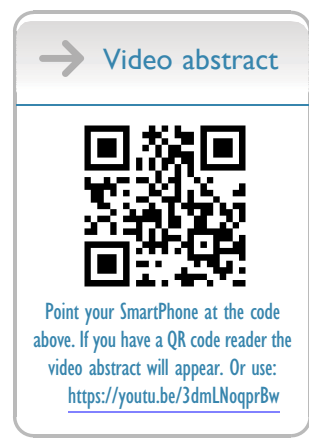

Correspondence: Haiyu Hong, Allergy Center, Department of Otolaryngology, The Fifth Affiliated Hospital of Sun Yat-sen University, No. 52, Meihua East Road, Zhuhai, 51 9020, People’s Republic of China, Email honghy@sysu.edu.cn

Yunping Fan, Department of Otolaryngology, The Seventh Affiliated Hospital of Sun Yat-sen University, Shenzhen, People's Republic of China, Email zhfanyp@163.com

*These authors contributed equally to this work

\begin{abstract}
The number of confirmed COVID-19 cases continues to rise around the world, which is a huge threat to the safety of people and the social economy. Despite the introduction of vaccines, effectively preventing and controlling the epidemic, especially in protecting vulnerable populations, remains a big challenge for countries worldwide. By summarizing the trajectory of several officially reported COVID-19 cases, we found that because the COVID-19 primary routes of transmission consist of respiratory droplets, aerosols and close contacts it remains containable with public health measures. Public health measures to contain the outbreak do not rely on the healthcare institution and government agencies alone but require the concerted efforts of the public with sustained vigilance and social responsibility. People who are showing symptoms or have had suspected contact need to keep wearing masks and be quarantined in time to prevent further chains of transmission.
\end{abstract}

Keywords: COVID-19, public health measures, masks wearing, social distancing, disease prevention, social responsibility

According to the report of World Health Organization, the number of confirmed COVID-19 cases around the world has surpassed $187,000,000^{1}$ as of early July 2021 and is continuing to rise, which is a great cause of alarm especially to the general public (add reference PMID: 33466996). The transmission of COVID-19 is rapid because of the high transmissibility of SARS-CoV-2 and its newly emerging variants. We reviewed the pandemic of COVID-19 in Chinese rural areas and learned that rural areas are highly vulnerable to public health crises. (add reference PMID: 33986599$)^{2,3}$ Strict quarantine has been successful in containing the spread of the pandemic, albeit at a huge cost to the national economy. ${ }^{4}$ Therefore, a better way to control the pandemic and protect the economy is needed based on the primary routes of transmission consisting of respiratory droplets, close contacts and potential aerosol disseminations, (add reference PMID: $34358292)^{5}$ in which all these routes remained containable via public health measures, as seen in China. 
It is shown that SARS-CoV-2 is transmitted through respiratory droplets, including airway secretions and saliva, and can be diagnosed with rapid antigen and quantitative polymerase chain reaction (qPCR). ${ }^{6}$ However, such tests might be a challenge to administer especially in the more rural areas (add reference PMID: 33986599). Hence, from following three cases in China, we found that public health measures extending to socially responsible behaviors of the general public such as mask wearing and social distancing, coupled with clear information from the government and public health institutes, work well to prevent secondary transmission (add reference PMID: 32842607). This is especially applicable to people with suspected exposure to the virus, during the potential virus incubation period.

The first case is Mr Zhang from Wuhan who arrived in Tibet by train having traveled from January 22nd to 24th, 2020, a journey of more than 2000 kilometers. He was subsequently diagnosed with COVID-19 infection on January 30th. As he was traveling from the epicenter of the outbreak, he wore a mask during the entire journey, kept a certain distance from others, and restricted his contact with others. When he developed symptoms, he continued his social distancing practice and went to the designated hospital in time. As a result, no infection was found in 32 of his close contacts. ${ }^{7}$ He remained the only COVID-19 case in Tibet, and had been included in our previous study. ${ }^{5}$

Another case is the first imported COVID-19 case from abroad confirmed in Shenzhen. The patient, Mr Sun, who now lives in Shenzhen City, worked in Bristol, UK for nearly two years. On February 27th, 2020, Mr Sun flew from London to Hong Kong (Flight CX250), then traveled from Hong Kong to Shenzhen by ferry (Ship 3A109) and finally took a taxi home. When entering the wharf, his temperature was normal after a journey of more than 6000 kilometers. Prior to his journey, Mr Sun reported contact with colleagues with flu-like symptoms, prompting him to wear a mask throughout his journey. Upon returning home, he practiced social distancing and stayed home until he developed a fever and went to the eighth Affiliated Hospital of Sun Yat-sen University, where he was diagnosed with COVID-19. After detailed investigation, there were 93 close contacts of the case, including his family contacts, the taxi driver, the ferry crew members, the ferry passengers and 2 customs contacts, none of whom contracted COVID-19. ${ }^{8}$

The last case is another overseas imported case from Lanzhou, Gansu province. Ms Li and her son left for Wuhan from Islamabad, Pakistan at about 9 pm on May 31st, 2020. It should be noted that she was diagnosed with COVID-19 on June 24th, but wore a mask and kept social distance when in contact with people during the times she was out. According to Local Centers for Disease Control and Prevention, all of Ms Li's close contacts wore masks during their contact with her, and they did not have any symptoms. ${ }^{9}$

The outbreak of COVID-19 has presented unprecedented challenges for public health and disease prevention. The transmission of SARS-CoV-2 and its variants is very efficient, in that one patient could reportedly transmit the disease to 2-3.5 other patients at the early stage. ${ }^{10-12}$ In addition to droplet transmission and direct contact, researchers detected SARS-CoV-2 in patients' gastrointestinal tract, saliva and urine. On the other hand, while there were cases of extensive spread, there also exist cases where none of the family members and close contacts of a taxi driver in Thailand were infected by the virus when the index patient wore a mask, reduced social contact and sought medical assistance in a timely manner. ${ }^{13}$ If these responsibilities were observed, isolation could be carried out in a timely manner and could prevent a chain of further transmission. As such, the public health measures taken to stem this outbreak is not a one-way street from the public health institutes but requires a concerted effort of constant vigilance and social responsibility from the general public as well. In addition, observing the responsibilities also means that mask usage can be prioritized for those showing symptoms and may be extended to those that travel from outbreak regions with heightened risk of exposure. This is in line with the mask usage policy of public health institutes of many nations such that mask stockpiles can be conserved for the frontline healthcare workers.

In conclusion, social responsibility of individuals, especially those traveling from areas with heightened risk of exposure, serves as a strong cooperative measure with public health institutes, and should continue to be observed despite the introduction of vaccines. It is also the best strategy for breaking the transmission chain, as demonstrated by the case studies presented. Such policies should be further communicated and used to educate the public on outbreak prevention as they are applicable for any respiratory communicable disease outbreaks. 


\section{Funding}

This study was supported by the National Natural Science Foundation of China (grant nos. 8207040234), Zhuhai Science and Technology Planning Project (grant nos. ZH22036201210047PWC).

\section{Disclosure}

The authors report no conflicts of interest in this work.

\section{References}

1. Coronavirus Resource Center Tracking Home [homepage on the Internet]. Baltimore: The Johns Hopkins Coronavirus Resource Center; 2021. Available from: https://coronavirus.jhu.edu/data. Accessed July 10, 2020.

2. Wang J, Zhang R. COVID-19 in rural China: features, challenges and implications for the healthcare system. J Multidiscip Healthc. 2021;14:10451051. doi:10.2147/JMDH.S307232

3. Zhang J, Zhang R. COVID-19 in China: power, transparency and governance in public health crisis. Healthcare (Basel). 2020;8(3):288. doi:10.3390/healthcare8030288

4. Xing C, Zhang R. COVID-19 in China: responses, challenges and implications for the health system. Healthcare (Basel). 2021;9(1):82. doi:10.3390/healthcare9010082

5. Guan W-J, Ni Z-Y, Hu Y; China Medical Treatment Expert Group for Covid-19. Clinical characteristics of coronavirus disease 2019 in China. $N$ Engl J Med. 2020;382(18):1708-1720. doi:10.1056/NEJMoa2002032

6. Khurshid Z, Asiri FYI, Al Wadaani H. Human saliva: non-invasive fluid for detecting novel coronavirus (2019-nCoV). Int J Environ Res Public Health. 2020;17(7):2225. doi:10.3390/ijerph17072225

7. 32 close contacts of the Covid-19 patient in Tibet are released today [homepage on the Internet]. Beijing: The Beijing News; 2020. Available from: http://www.bjnews.com.cn/news/2020/02/08/686297.html. Accessed July 10, 2020.

8. A case of imported confirmed case was reported in Shenzhen, with 93 confirmed close contacts [homepage on the Internet]. Beijing: The Beijing News; 2020. Available from: http://www.bjnews.com.cn/news/2020/03/01/697550.html. Accessed March 13, 2020.

9. Announcement of the Office of the Leading Group for Joint Prevention and Control of the New Coronary Pneumonia Epidemic in Qilihe District on the information of a confirmed case of imported new coronary pneumonia [homepage on the Internet]. Lanzhou: Qilihe People's Government; 2021. Available from: http://www.qilihe.gov.cn/art/2021/6/24/art_1459_1014764.html. Accessed July 10, 2020.

10. Wu JT, Leung K, Leung GM. Nowcasting and forecasting the potential domestic and international spread of the 2019-nCoV outbreak originating in Wuhan, China: a modelling study. Lancet. 2020;395(10225):689-697. doi:10.1016/S0140-6736(20)30260-9

11. Riou J, Althaus CL. Pattern of early human-to-human transmission of Wuhan 2019 novel coronavirus (2019-nCoV), December 2019 to January 2020. Euro Surveill. 2020;25(4):2000058. doi:10.2807/1560-7917.ES.2020.25.4.2000058

12. Rocklöv J, Sjödin H, Wilder-Smith A. COVID-19 outbreak on the Diamond Princess cruise ship: estimating the epidemic potential and effectiveness of public health countermeasures. J Travel Med. 2020;27(3):taaa030. doi:10.1093/jtm/taaa030

13. Pongpirul WA, Pongpirul K, Ratnarathon AC, Prasithsirikul W. Journey of a Thai taxi driver and novel coronavirus. $N$ Engl J Med. 2020;382 (11):1067-1068. doi:10.1056/NEJMc2001621

\section{Publish your work in this journal}

Risk Management and Healthcare Policy is an international, peer-reviewed, open access journal focusing on all aspects of public health, policy, and preventative measures to promote good health and improve morbidity and mortality in the population. The journal welcomes submitted papers covering original research, basic science, clinical \& epidemiological studies, reviews and evaluations, guidelines, expert opinion and commentary, case reports and extended reports. The manuscript management system is completely online and includes a very quick and fair peer-review system, which is all easy to use. Visit http://www.dovepress.com/testimonials.php to read real quotes from published authors. 